\title{
TRPC3 as a Target of Novel Therapeutic Interventions
}

\author{
Oleksandra Tiapko (1D) and Klaus Groschner* \\ Gottfried-Schatz-Research-Center-Biophysics, Medical University of Graz, Neue Stiftingtalstrasse 6/D04, \\ 8010 Graz, Austria; oleksandra.tiapko@medunigraz.at \\ * Correspondence: klaus.groschner@medunigraz.at; Tel.: +43-316-385-71500
}

Received: 10 June 2018; Accepted: 20 July 2018; Published: 22 July 2018

\begin{abstract}
TRPC3 is one of the classical members of the mammalian transient receptor potential (TRP) superfamily of ion channels. TRPC3 is a molecule with intriguing sensory features including the direct recognition of and activation by diacylglycerols (DAG). Although TRPC3 channels are ubiquitously expressed, they appear to control functions of the cardiovascular system and the brain in a highly specific manner. Moreover, a role of TRPC 3 in immunity, cancer, and tissue remodeling has been proposed, generating much interest in TRPC 3 as a target for pharmacological intervention. Advances in the understanding of molecular architecture and structure-function relations of TRPC3 have been the foundations for novel therapeutic approaches, such as photopharmacology and optochemical genetics of TRPC3. This review provides an account of advances in therapeutic targeting of TRPC 3 channels.
\end{abstract}

Keywords: transient receptor potential channels; TRPC3 pharmacology; channel structure; lipid mediators; photochromic ligands

\section{Introduction to TRPC3}

Mammalian transient receptor potential (TRP) channels of the classical subfamily (TRPC) are closely related to the founding member dTRP, which was discovered as a critical element in Drosophila visual transduction [1]. In human tissues, TRPCs typically serve signal transduction pathways downstream of $G$ protein-coupled receptors [2]. All TRPCs are controlled by and able to sense membrane lipids $[3,4]$, where TRPC $3 / 6 / 7$ channels display a direct mechanism of activation via diacylglycerols $[5,6]$, which is generated in response to receptor-phospholipase $C$ pathways. Like all other TRPC channels, TRPC 3 features six transmembrane spanning segments with nitrogen $(\mathrm{N})$ and carbon (C) termini residing in the cytoplasm. TRPC3 assembles into tetrameric complexes in which the cytoplasmic termini interact to form an inverted bell-shaped cytoplasmic layer, as revealed by single-particle cryo-electron microscopy (cryo-EM) $[7,8]$. The tetrameric assembly constitutes a cation permeation path with a selectivity filter harboring negatively charged residues (E630 in the 848aa variant; isoform 3/Q13507-3 in UniProt) to determine calcium ion $\left(\mathrm{Ca}^{2+}\right)$ transport within the pore domains, connecting transmembrane domains 5 and 6 (TM5 and TM6) [7,9]. Multiple cytoplasmic regulatory domains have been identified, including a highly conserved proline-rich and calmodulin $/ \mathrm{IP}_{3}$ receptor binding (CIRB) region in the C-terminus $[10,11]$, which enable the channel to serve multimodal signaling functions. Initially, the channel was implicated in store-operated $\mathrm{Ca}^{2+}$ entry processes $[12,13]$ but later on, a consent was reached among researchers that the prominent mechanism of TRPC3 activation and TRPC3-mediated $\mathrm{Ca}^{2+}$ signaling is based on a direct interaction with diacylglycerol. This was found to occur within a lateral gating fenestration of the pore domain [14]. Like its DAG-sensitive relatives TRPC6 and TRPC7, TRPC3 has been implicated in a wide array of pathologies and disorders ranging from tumors to cardiac arrhythmias [15]. Notably, expression of TRPC3 varies among tissues and their developmental state as well as cell phenotype. 
A prominent functional role of TRPC 3 has been detected in both proliferating cells, such a vascular progenitors [16,17], but also in differentiated cell types [18,19]. Overall, pharmacological targeting of TRPC 3 with high specificity and spatiotemporal precision has become feasible and emerged as an attractive perspective in TRPC pharmacology.

\section{Potential Role of TRPC3 in Human Disease}

$\mathrm{Ca}^{2+}$ influx is an essential determinant of cell function and fate, and TRPC 3 serves to regulate $\mathrm{Ca}^{2+}$ entry via its nonselective permeation pathway by multiple mechanisms, including functional interaction with the sodium-calcium exchanger NCX1 [20-23]. TRPC3 mRNA was detected in both excitable and non-excitable cells, and changes in expression levels are reportedly correlated with pathological processes and organ disorders [24]. A gain in TRPC3 function was found to be associated with pathologies of the cardiovascular system and brain. In the heart, TRPC 3 channels were confirmed as a major target of the angiotensin II- and noradrenaline-induced nuclear factor of activated $\mathrm{T}$ cells (NFAT) activation involved in maladaptive cardiac remodeling and arrhythmias $[20,22,25,26]$. TRPC 3 overexpression and/or gain-of-function depolarizes myocytes, promotes the calcineurin/NFAT pathway, is involved in adverse mechanical stress responses, hypertrophy, and heart failure $[25,26]$. Importantly, NFAT signaling in myocytes has been linked to direct $\mathrm{Ca}^{2+}$ entry via TRPC3 channels [27]. Nonetheless, the pathophysiologicial role of TRPC 3 in the heart appears, for a large part, to be based on its expression and function in cardiac fibroblasts. TRPC 3 was identified as a crucial player in the proliferation and differentiation of fibroblasts in the myocardium and its activity was found to promote fibrosis, structural remodeling and arrhythmias, specifically atrial fibrillation [28-30].

TRPC 3 channels are also expressed in other cardiovascular cells, including vascular smooth muscle and endothelial cells [31-33]. TRPC3 has been proposed to govern both the fate of endothelial progenitor cells and functions in the mature endothelium specifically vasodilatory responses [16]. TRPC3-mediated $\mathrm{Ca}^{2+}$ was reported to trigger NO-mediated [34] and NO-independent vasodilation [33]. For vascular smooth muscle, Dietrich et al. showed that up-regulated expression of TRPC3 channels, which features constitutive activity, is associated with high blood pressure in TRPC6-deficient mice [35]. Similar to cardiac muscle, a role of TRPC3 in phenotype transitions and vascular remodeling was suggested [36].

TRPC 3 expression is detectable throughout the brain with prominent levels in cerebellar Purkinje cells in the adult mouse brain [37]. Notably, up-regulation of the neuronal TRPC3 conductance by the gain-of-function mutation T635A (moonwalker; Mwk) was shown to lead to $\mathrm{Ca}^{2+}$-dependent degradation of Purkinje cells and, as a consequence, to impaired motor coordination $[38,39]$. In the hippocampus, TRPC 3 activity was found to be negatively correlated with contextual fear memory [40].

A role in non-excitable cell signaling was proposed for the immune system. TRPC 3 was reported to control $\mathrm{Ca}^{2+}$ waves and to facilitate the response to antigen stimulation [41]. Phillip et al. detected defects in the TRPC3 gene of immune cell lines with impaired $\mathrm{Ca}^{2+}$ signaling, which were initially described by Fanger et al. [42]. Phillip et al. were able to restore the $\mathrm{Ca}^{2+}$ influx and activation of T-cells by overexpression of functional TRPC 3 channels [43]. Hence, TRPC 3 was suggested to contribute to $\mathrm{Ca}^{2+}$ signaling in immune cells alongside the prominent players stromal interaction molecule (STIM) and Orai, which constitute the classical calcium release-activated $\mathrm{Ca}^{2+}$ channel (CRAC) conductance [44].

Growing consensus states that TRPC molecules impact on nearly all "cancer hallmarks" and drive cancer progression [45]. In particular, TRPC3 was found as an ion channel that governs proliferation and migration of a variety of tumor cells, including melanoma [46], lung [47], bladder [48], ovarian [49], and breast [50] cancers.

Current knowledge on the role of TRPC 3 in most investigated pathologies suggests that channel blockers might be suitable for disease management. This has been suggested for cardiac fibrosis and hypertrophy [29,51], coronary stenosis [36], and melanoma [46]. Nonetheless, for certain disorders, selective block of TRPC 3 channel functioning might not be a useful therapeutic strategy since the 
protein's cellular role is more complex, and TRPC3 function has also been assigned to beneficial effects, such as stabilization of cardiac contractility, and excitability and vasodilation or promotion of immune responses. Not only should the expression levels and overall channel activity be considered, but also the cell-type specific signaling signature of TRPC 3 channels, which depends on factors like subcellular localization, composition of pore complex, and input signaling pattern, and are likely of relevance for disease etiology. The ability of TRPC proteins to assemble into specific heteromeric complexes, for which stoichiometry is likely to determine signaling features as well as sensitivity to pharmacological intervention, has long been recognized [52-54]. Moreover, native TRPC channels have been shown to operate in cell-specifically organized signalplexes, which enable efficient interactions with downstream signaling elements, such as $\mathrm{CaN}$ [27] or the electrogenic $\mathrm{Ca}^{2+}$ signaling partner NCX1 [22]. Dynamic organization of TRPC3 into such cell-type specific signalplexes, along with the TRPC channels cycling between activated, inactivated, and desensitized states, needs consideration as a basis of cell-type specific signaling and therapeutic targeting of TRPC3. In this context, more refined pharmacological interventions including also channel activators and modulators might be of value for therapeutic applications.

\section{Pharmacological Inhibitors}

Early attempts to identify and characterize TRPC 3 channel function were based on non-specific channel blockers, such as the trivalent cations $\mathrm{La}^{3+}$ and $\mathrm{Gd}^{3+}[12,55,56]$, or commonly used nonselective inhibitors of receptor-mediated $\mathrm{Ca}^{2+}$ entry, verapamil or SKF96365 [55]. Due to their wide range of targets, these blockers were only of limited use for the characterization of TRPC3 in native tissues and not suitable for the development of therapeutic application. A first step toward the more specific targeting of TRPC 3 function was achieved by He et al., showing that the 3,5-bis(trifluoromethyl)pyrazole (YM-58483 or BTP2), which was initially described as an inhibitor of T-lymphocytes store-operated $\mathrm{Ca}^{2+}$ entry (SOCE) [57,58], was inhibiting TRPC3 channel activity in different cell types including DT40 B-lymphocytes [59]. Based on the observation of BTP2 inhibition of TRPC3 conductance activated by carbachol (CCh) or oleoyl-acetyl glycerol (OAG; Figure 1) [59], these authors clearly identified the pyrazole derivative as an inhibitor of TRPC3. Since BTP2 still lacked appreciable selectivity among different $\mathrm{Ca}^{2+}$ entry pathways, Kiyonaka et al. synthesized and characterized a series of pyrazole derivatives to discriminate between SOCE, TRPC, 3 and other TRPC isoforms. These authors reported a new pyrazole 3 (Pyr3) inhibitor of TRPC channels (Figure 1) with a striking preference for TRPC3. Notably, $3 \mu \mathrm{M}$ of Pyr3, which effectively inhibited TRPC3, failed to suppress TRPC6, TRPM2, TRPM4, and TRPM7 channels overexpressed in HEK293 cells. Pyr3 was suggested to inhibit TRPC 3 channels from the extracellular side and photoaffinity labeling of Pyr3 showed a strong incorporation of the inhibitor into TRPC3 but not into TRPC6 channels [60]. The exact site of molecular interaction has not been clearly defined, and even a principle blocking mechanism by occluding the permeation pathway has not been conclusively delineated. Pyr3 certainly advanced the field by enabling a pharmacological dissection of closely related TRPC channel subtypes. However, later investigations on the selectivity of pyrazole inhibitors demonstrated that Pyr3 inhibits STIM/Orai $\mathrm{Ca}^{2+}$ entry complexes [61]. The latter authors identified other pyrazole derivatives that are indeed able to discriminate between TRPC 3 and Orai-mediated SOCE, including an acceptably selective TRPC3 blocker (Pyr10). This pyrazole blocked recombinant, homomeric TRPC3 channels were highly potent $\left(\mathrm{IC}_{50}>0.72 \mu \mathrm{M}\right)$ but affected SOCE only at concentrations more than one order of magnitude higher $\left(\mathrm{IC}_{50}>10 \mu \mathrm{M}\right)[61]$. 


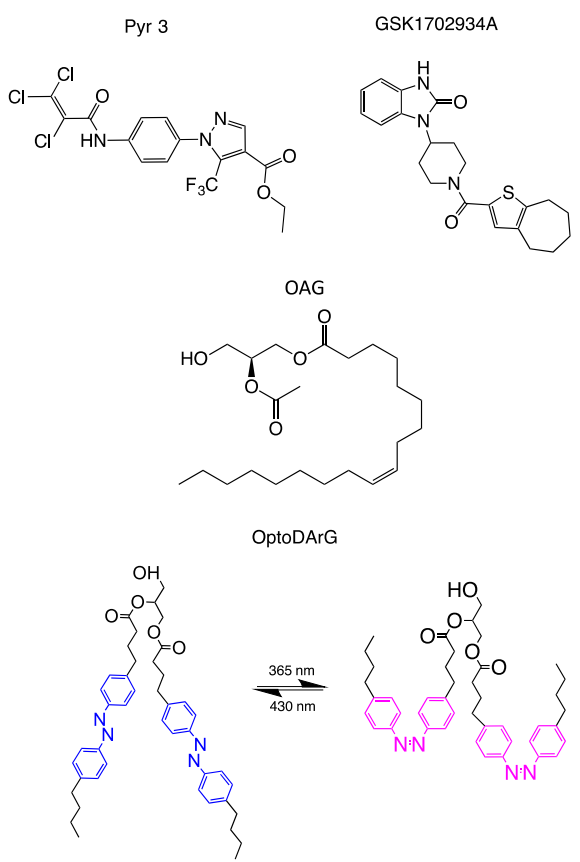

Figure 1. Chemical structures of prototypical antagonist and agonists of transient receptor potential channel 3/6 (TRPC3/6): Pyrazole 3 (Pyr3) as a most commonly used pore blocker; GSK1702934A and 2-Acetyl-1-oleoyl-sn-glycerol (OAG) represent channel agonists (a synthetic, non-lipid activator, and a diacylglycerol/lipid, respectively); OptoDArG as a photochromic agonist (photoswitchable lipid) and a powerful tool for precise control of TRP channels (TRPC) activity.

Another screening study by Washburn et al. identified two potent and selective thiazole inhibitors of TRPC channels. These compounds, assigned GSK2332255B (GSK255B) and GSK2833503A (GSK503A), are anilino-thiazoles and feature a nanomolar potency for blocking TRPC6 and TRPC3 and reportedly lack significant effects on many other calcium-permeable channels [62]. Since TRPC3/6 channels were implicated in the pathogenesis of hypertension and hypertrophy, GSK255B and GSK503A were tested in animal models of cardiac hypertrophy and remodeling. GSK255B and GSK503A, most likely by a combined suppression of TRPC3 and TRPC6 conductance, reduced hypertrophy and fibrosis induced by pressure overload in rodents [63].

Other TRPC3 blocking agents with ill-defined selectivity have been introduced, such as norgestamate [64], HC-C3A [40], 4-(\{(1R,2R)-2-[(3R)-3-aminopiperidin-1-yl]-2,3-dihydro-1 $H$-inden-1-yl\}oxy)-3-chlorobenzonitrile (SAR7334) [65], and 2-(benzo[d][1,3]dioxol-5-ylamino)thiazol4-yl)((3S,5R)-3,5-dimethylpiperidin-1-yl)methanone (BTDM) [8]. The latter compound (BTDM), albeit incompletely characterized at the cellular and tissue level, was able to delineate TRPC6 and TRPC3 structure by cryo-EM [8]. Consequently, a BTDM binding site was localized within the TRPC6 tetrameric complex (Figure 1). Importantly, another study resolving the TRPC3 structure by cryo-EM [7] identified a highly charged extracellular cavity with close structural relation to the pore domain, therefore representing a potential interaction site for inhibitors and/or modulators of the channel. Thus, the first high-resolution structural information on the drug binding site in the TRPC 3 complex has emerged, and this information will promote the development of therapeutic targeting of TRPC3 (Figure 1).

\section{Endogenous and Synthetic Channel Activators}

A hallmark of the cellular regulation of mammalian TRPC channels is the intimate linkage between channel activity and membrane lipid composition. TRPC 3 is, for a large part, governed by its membrane lipid environment. Not only production of diacylglycerols (DAGs; Figure 1) in 
response to phospholipase C (PLC) activation activates the channel, but also phosphatidylinositol 4,5-bisphosphate PIP $_{2}$ as a precursor of DAG formation, has been identified as a determinant of TRPC3 activity [66]. Both PIP 2 and DAG appear to promote channel activity. Synthetic and photoswitchable DAGs have been introduced as activators that enable optical control of TRPC3 activity. As a highly active, unnatural lipid activator, a DAG with two arachidonyl-mimicking azobenzene moieties was introduced (OptoDArG; Figure 1) [14]. In addition to glycerol derivatives, membrane cholesterol was shown to initiate and enhance TRPC 3 activity [67]. The effect of cholesterol was attributed in part by enhanced recruitment of the channel into the plasma membrane. Importantly, two distinct regulation mechanisms were reported for TRPC channels including TRPC 3 in particular. This is, on the one hand, an increase in the open probability in membrane resident channels, as shown at the level of single TRPC3 channels for PLC-mediated activation, which is characterized by destabilized closed channel conformations [14]. On the other hand, the recruitment of a vesicular pool of TRPC channels into the plasma membrane was proposed. Through this mechanism, certain activating stimuli might enhance channel availability, and thereby TRPC3 currents and downstream signaling [68]. In this respect, TRPC3, in contrast to its close relative TRPC6, displays constitutive activity in resting cells, at essentially low PLC activity. Suppressed basal activity in TRPC6 was found to be related to the channel's glycosylation pattern. Dual glycosylation at two asparagine residues was found to be crucial for maintaining the basal activity of TRPC6 low compared to monoglycosylated TRPC3, which is marginally permeable for ions in a resting state [69]. Constitutive gating activity appears largely independent of basal levels of DAGs in the membrane, as a DAG-insensitive mutant (G652A) of TRPC3 retained constitutive activity [14]. The same mutation also retained sensitivity to activation by a synthetic activator GSK1702934A (GSK; Figure 1) that clearly acts in manner different from DAGs to enhance the open probability of TRPC3 [14]. Xu et al. introduced this small and apparently selective agonist of ligand-gated TRPC channels, which activated TRPC $3 / 6$ overexpressed in HEK293 cells and increased the perfusion pressure of isolated rat heart and transiently increased blood pressure in conscious Sprague Dawley rats [70]. Later, Qu et al. introduced a series of TRPC-selective agonists, which lacked effects on other members of the TRP family (TRPA, TRPM, and TRPV). These agonists were pyrazolopyrimidine-based and remarkably potent $\left(\mathrm{EC}_{50}\right.$ in the nanomolar range) in the activation of recombinant TRPC3, TRPC6, and TRPC7 channels [71]. These synthetic small molecule agonists of TRPC channels (GSK-related and pyrazolopyrimidine-based structures) appear to bypass the PLC pathway and the TRPC lipid-gating machinery. Importantly, GSK has been found to exert little to no effect on membrane conductance of cardiomyocytes at an essentially low level of TRPC 3 expression in the murine heart, but induced TRPC 3 currents when the channel was overexpressed in a genetic mouse model [22]. This indicates a relatively high specificity of the GSK activator for TRPC3/6/7 channels, since none of the abundant voltage-gated cardiac conductances were affected [22]. For pyrazolopyrimidine-based agonists, Qu et al. confirmed the selectivity and efficiency in stimulating endogenous TRPC3/6 activity in rat primary glomerular mesangial cells by $\mathrm{Ca}^{2+}$ measurements [71]. Of note, limited therapeutic interest has been expressed as of yet for synthetic activators of TRPC 3 , since most TRPC3-associated pathologies are related to either an enhanced expression or a gain in function of phenotypes. Hence, drug development activities have focused primarily on selective antagonists or blockers of the channel. Nonetheless, TRPC 3 has been identified as promoting proliferative cell phenotypes $[16,29,36]$ and may be involved not only in maladaptive tissue remodeling but also in tissue regeneration. Therefore, unconventional approaches that provide high spatial precision of intervention, such as photopharmacology, may create the possibility of a therapeutic application for TRPC 3 activators.

\section{New Insights into the Ligand Binding Domains in TRPC3}

The delineation of TRPC3 and TRPC6 structures by cryo-EM microscopy approaches succeeded in the localization of potential binding sites for blockers, modulators, as well as endogenous lipids. Tang et al. presented the structure of homotetrameric TRPC 3 complexes at $4.4 \AA$ [7]. A resolution 
along with the structure of TRPC6 (3.8 ^ resolution), in which binding of the high affinity inhibitor BTDM was localized between the S1-S4 voltage sensor-like domain (VSLD) and the pore domain. This is a position in which an interaction is likely to hinder gating movements (Figure 1). The BTDM binding site is conserved between TRPC 6 and TRPC 3 , and interaction of this potent inhibitor structure with the channel appears not to overlap with lipid regulation, as some mutations that prevent BTDM binding did not interfere with activation by DAGs. Tang et al. performed a structure analysis of TRPC3 reconstituted into nanodiscs in the presence of the diacylglycerol activator OAG, but obtained a closed channel conformation and could not discern the presence of the lipid activator [8]. Fan et al. reported the structure of tetrameric TRPC 3 complexes in a lipid-occupied closed state at a $3.3 \AA$ resolution and localized two lipid interaction sites without identifying the molecular nature of the lipid species [7]. One lipid molecule occupied a position between a pre-S1 elbow-like structure and the S4-S5 linker representing a pivotal element of TRPC gating. A second lipid-like density was found within a lateral fenestration in the pore domain (Figure 2). This second and potentially lipid-interaction site is close to the previously recognized critical LFW motif in the pore domain. It was identified by our laboratory as a structure essential for DAG recognition and lipid gating in the channel using homology modeling combined with structure-guided mutagenesis and a novel optical lipid-clamp approach [14]. Observation of a closed channel state may reflect either a desensitized or inactivated state of the channel or the presence of an inert, non-activating lipid species that occupies the channel in its resting state.

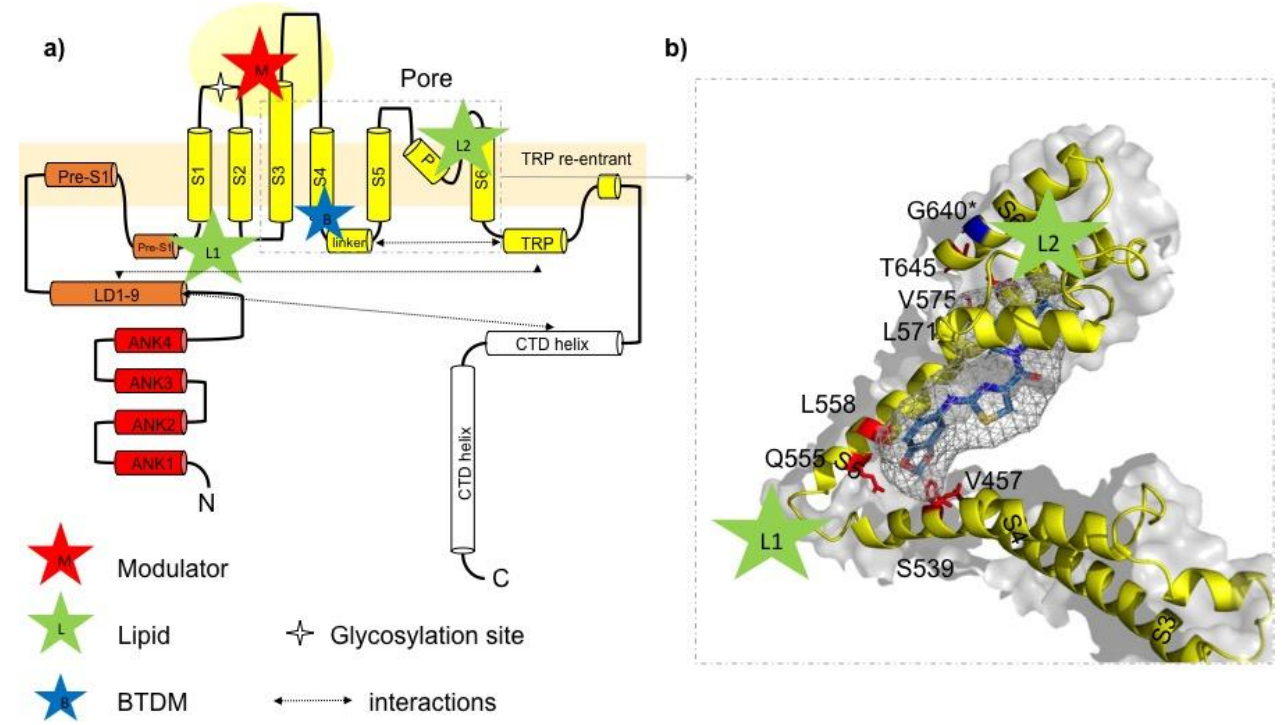

Figure 2. Ligand-channel interactions and potential drug binding sites in TRPC3. (a) Schematic illustration of the domain structure of one TRPC3 channel subunit according to information provided in Fan et al. [7]. Lipid binding sites (green stars) are indicated with L1 (formed by LD9, pre-S1, S1, S4, and S4-S5 linker) and L2 (between p-loop and S6 helix); potential modulator binding site (M) represented by a cavity (extracellular domain) formed by the extended S3 helix, S1-S2 and S3-S4 linkers as previously identified [7]. Proposed BTDM binding site formed by S3, S4-S5 linker, S4, S5, and S6 identified by Tang et al. [8]. (b) Detailed view on postulated 2-(benzo[d][1,3]dioxol-5-ylamino)thiazol-4-yl) $((3 S, 5 R)-3,5-d i m e t h y l p i p e r i d i n-1-y l) m e t h a n o n e(B T D M)$ binding site in TRPC3: amino acids in the TRPC3 sequence, corresponding to the TRPC6 BTDM binding site are marked in red. The BTDM molecule is only schematically introduced into the TRPC structure and not adjusted in size. The glycine residue G652 (here G640, isoform 1/Q13507-1 in UniProt) identified as crucial for recognition and accommodation of lipid activators is highlighted in blue [14]. The BTDM molecule is schematically placed into the proposed binding site. 
Both natural as well as synthetic modulators are likely to occupy distinct binding pockets to interfere with the gating machinery involving conformational changes in both the S1-S4 VSLD and the pore domains. Fan et al. identified a charged extracellular cavity formed by an extended S3 helix and the S3-S4 linker. This extracellular domain connects to the pore domain via hydrophobic interactions and represents a potential extracellular modulatory site for small molecules including pyrazole inhibitors [7].

Importantly, these advances in TRPC 3 structural biology have created a basis for further advances with TRPC3 synthetic biology in terms of optogenetics and photopharmacology as outlined below. Availability of structural information at the atomic level will allow for tethered ligand approaches and optogating by crosslinking domains recognized as gating elements.

\section{TRPC3 Photopharmacology-A Therapeutic Perspective}

Therapeutic targeting of a multifunctional signaling molecule that is expressed in a wide range of tissues, as is the case for TRPC3 [23], typically requires refined pharmacological strategies to obtain sufficient tissue and/or cell-type specificity for clinically useful interventions. Of note, information on the viability in a genetic mouse model, which lacks expression of all TRPC species [72], indicated that the nonselective and simultaneous block of multiple TRPC conductances might not necessarily generate severe side effects in healthy tissues and organs. It is tempting to speculate that the impact of TRPC 3 in organ dysfunction is based on either a certain expression profile of TRPC genes and/or a certain cell- or phenotype-dependent signaling signature of TRPC 3 , along with its closer relatives in diseased states. Hence, gaining understanding on the cell-type specific function of these channels in normal and pathological states is important. Cell-type specific interventions might be achievable by manipulating TRPC3 signaling in a spatiotemporally precise manner using photopharmacology.

Initial attempts adopted the caged ligand concept to gain optical control over TRPC channels [73]. This approach was based on the availability of caged lipid activators of TRPC $3 / 6$ channels. DAGs were fused to coumarin and nitroveratroyl molecules to prevent immediate interaction with their biological targets [74]. A significant increase in $\mathrm{Ca}^{2+}$ was generated in HeLa cells, which endogenously express TRPC 3 and TRPC6 channels upon photorelease of the active lipid mediator with ultraviolet (UV)-A light. Notably, caged stearyl-arachinonyl-glycerol (SAG) was found to be the most potent agonist amongst different DAGs, consistent with the initial characterization of lipid sensitivity by Hofmann et al. [5]. Photoreleased SAG triggered the most sustained and largest increase in $\mathrm{Ca}^{2+}$ concentrations compared with other lipid activators, such as stearyl-linoenyl- and 1,2-dioctanoyl-glycerol. $\mathrm{NiCl}_{2}$ and TRPC non-selective blocker SKF-96365 almost completely suppressed response in HeLa cells to lipid uncaging, suggesting a TRPC-dependent $\mathrm{Ca}^{2+}$ influx [74].

Disadvantages of the caged-lipid approach include the principle irreversibility of the chemical switch and the unavoidable generation of a second molecular structure represented by the released cage. Tiapko et al. clearly showed the undesirable off-target effect with the caged lipid strategy. Photorelease of caged 1,2-DOG was found to generate an artifact caused by UV light application in the presence of the generated free coumarin moiety, whereas the UV light itself did not affect membrane conductance. Hence, off-target effects, due to the phototoxicity of the caging structure, requires consideration and is expected to limit the therapeutic value of caged ligand strategies [75].

As an alternative approach, the photochromic ligand approach has been successfully adopted for TRPC photopharmacology $[14,76]$. Herein, the structure and activity of the ligand was reversibly controlled by light. As a conformation-flexible, light-sensing structure, azobenzene was introduced into the DAG structure. The biological activity of these photochromic activators is controlled by cis-trans photoisomerization of the azobenzene, which resides within the aliphatic side chains of the DAG. Azobenzene-modified DAGs successfully served as tools for studying TRPC cell-specific functions as well as ligand-protein interactions and channel activation-deactivation kinetics [14,76-78].

Initial characterization of different photochromic DAGs demonstrated precise and reversible control of $\mathrm{Ca}^{2+}$ signals in HeLa cells, with probes designated as PhoDAGs. PhoDAG-1 resembles 
SAG with the arachidonyl side chain replaced by a corresponding structural element containing the azobenzene moiety. Two other structurally related lipids were predicted to functionally mimic 1,2-DOG (PhoDAG-2 and PhoDAG-3). Typically, the trans-conformation exerted little or no effect on intracellular $\mathrm{Ca}^{2+}$, whereas cis-adopted molecules efficiently triggering $\mathrm{Ca}^{2+}$ influx through the plasma membrane. These actions were fully reversible and allowed for precise cyclic control of the signaling function [78].

With these new tools, Leinders-Zufall et al. demonstrated manipulation of mTRPC2 channels, endogenously expressed in neurons of murine sensory neurons from main olfactory and vomeronasal epithelium. As localization of these channels is confined to certain cell types and cellular structures, the spatial precision of the new technology provided important insight into DAG-sensitive TRPC2 function in the mouse olfactory system [76]. In another study, a photochromic DAG, containing two arachidonic acid-mimicking photochromic moieties, designated as OptoDArG, was introduced and successfully used to investigate the lipid sensing machinery [14]. This study used the intriguing temporal precision of the method and uncovered not only a structural element involved in lipid recognition by TRPC3, but also a cooperative slow gating processes, residing in a subunit interface within the pore domain. Such cooperative gating processes are potentially important determinants of frequency dependence of signaling, thereby generating specific signaling signatures dependent on complex composition, cellular localization of the complexes, or upstream signaling patterns. Detailed elucidation of celland phenotype-specific TRPC3 signaling features appears to be an essential next step toward the therapeutic targeting of this molecule.

\section{Conclusions}

Emerging technologies for precise spatiotemporal manipulation of the activity of TRPC channels by light, along with an increase in available structural information on drug interaction sites and gating processes in TRPC channels, are expected to promote the development of novel therapeutic concepts. TRPC photopharmacology will advance the field by enabling exact control over gating pattern, the option of spatially precise manipulation, as well as by providing a basis for efficient all-optical drug screening. As such, cell-type and tissue-specific targeting of TRPC 3 and respective interventions of therapeutic value appear feasible and are awaited.

Funding: APC was sponsored by MDPI. Oleksandra Tiapko is member of the funded PhD program "Metabolic and Cardiovascular Disease" and was funded by the Austrian Science Fund (FWF W1226-B18).

Conflicts of Interest: The authors declare no competing interests.

\section{References}

1. Minke, B.; Cook, B. TRP channel proteins and signal transduction. Physiol. Rev. 2002, 82, 429-472. [CrossRef] [PubMed]

2. Zhu, X.; Jiang, M.; Peyton, M.; Boulay, G.; Hurst, R.; Stefani, E.; Birnbaumer, L. Trp, a novel mammalian gene family essential for agonist-activated capacitative $\mathrm{Ca}^{2+}$ entry. Cell 1996, 85, 661-671. [CrossRef]

3. Svobodova, B.; Groschner, K. Mechanisms of lipid regulation and lipid gating in TRPC channels. Cell Calcium 2016, 59, 271-279. [CrossRef] [PubMed]

4. Storch, U.; Forst, A.-L.; Pardatscher, F.; Erdogmus, S.; Philipp, M.; Gregoritza, M.; Mederos y Schnitzler, M.; Gudermann, T. Dynamic NHERF interaction with TRPC4/5 proteins is required for channel gating by diacylglycerol. Proc. Natl. Acad. Sci. USA 2017, 114, E37-E46. [CrossRef] [PubMed]

5. Hofmann, T.; Obukhov, A.G.; Schaefer, M.; Harteneck, C.; Gudermann, T.; Schultz, G. Direct activation of human TRPC6 and TRPC3 channels by diacylglycerol. Nature 1999, 397, 259-263. [CrossRef] [PubMed]

6. Beck, B.; Zholos, A.; Sydorenko, V.; Roudbaraki, M.; Lehen'kyi, V.; Bordat, P.; Prevarskaya, N.; Skryma, R. TRPC7 is a Receptor-Operated DAG-Activated Channel in Human Keratinocytes. J. Investig. Dermatol. 2006, 126, 1982-1993. [CrossRef] [PubMed] 
7. Fan, C.; Choi, W.; Sun, W.; Du, J.; Lu, W. Structure of the human lipid-gated cation channel TRPC3. eLife 2018, 7, e36852. [CrossRef] [PubMed]

8. Tang, Q.; Guo, W.; Zheng, L.; Wu, J.-X.; Liu, M.; Zhou, X.; Zhang, X.; Chen, L. Structure of the receptor-activated human TRPC6 and TRPC3 ion channels. Cell Res. 2018, 28, 746-755. [CrossRef] [PubMed]

9. Lichtenegger, M.; Stockner, T.; Poteser, M.; Schleifer, H.; Platzer, D.; Romanin, C.; Groschner, K. A novel homology model of TRPC3 reveals allosteric coupling between gate and selectivity filter. Cell Calcium 2013, 54, 175-185. [CrossRef] [PubMed]

10. Vazquez, G.; Wedel, B.J.; Aziz, O.; Trebak, M.; Putney, J.W., Jr. The mammalian TRPC cation channels. Biochim. Biophys. Acta (BBA) Mol. Cell Res. 2004, 1742, 21-36. [CrossRef] [PubMed]

11. Wang, Y.; Bu, J.; Shen, H.; Li, H.; Wang, Z.; Chen, G. Targeting Transient Receptor Potential Canonical Channels for Diseases of the Nervous System. Curr. Drug Targets 2017, 18, 1460-1465. [CrossRef] [PubMed]

12. Vazquez, G.; Lievremont, J.P.; Bird, G.S.J.; Putney, J.W. Human Trp3 forms both inositol trisphosphate receptor-dependent and receptor-independent store-operated cation channels in DT40 avian B lymphocytes. Proc. Natl. Acad. Sci. USA 2001, 98, 11777-11782. [CrossRef] [PubMed]

13. Trebak, M.; Bird, G.S.J.; McKay, R.R.; Putney, J.W., Jr. Comparison of Human TRPC3 Channels in Receptor-activated and Store-operated Modes. J. Biol. Chem. 2002, 277, 21617-21623. [CrossRef] [PubMed]

14. Lichtenegger, M.; Tiapko, O.; Svobodova, B.; Stockner, T.; Glasnov, T.N.; Schreibmayer, W.; Platzer, D.; Cruz, G.G.; Krenn, S.; Schober, R. An optically controlled probe identifies lipid-gating fenestrations within the TRPC3 channel. Nat. Chem. Biol. 2018, 14, 1-9. [CrossRef] [PubMed]

15. Xiao, X.; Liu, H.-X.; Shen, K.; Cao, W.; Li, X.-Q. Canonical Transient Receptor Potential Channels and Their Link with Cardio/Cerebro-Vascular Diseases. Biomol. Ther. (Seoul) 2017, 25, 471-481. [CrossRef] [PubMed]

16. Poteser, M.; Graziani, A.; Eder, P.; Yates, A.; Mächler, H.; Romanin, C.; Groschner, K. Identification of a rare subset of adipose tissue-resident progenitor cells, which express CD133 and TRPC3 as a VEGF-regulated $\mathrm{Ca}^{2+}$ entry channel. FEBS Lett. 2008, 582, 2696-2702. [CrossRef] [PubMed]

17. Hao, H.B.; Webb, S.E.; Yue, J.; Moreau, M.; Leclerc, C.; Miller, A.L. TRPC3 is required for the survival, pluripotency and neural differentiation of mouse embryonic stem cells (mESCs). Sci. China Life Sci. 2018, 61, 253-265. [CrossRef] [PubMed]

18. Li, H.S.; Xu, X.Z.; Montell, C. Activation of a TRPC3-dependent cation current through the neurotrophin BDNF. Neuron 1999, 24, 261-273. [CrossRef]

19. Facemire, C.S.; Mohler, P.J.; Arendshorst, W.J. Expression and relative abundance of short transient receptor potential channels in the rat renal microcirculation. Am. J. Physiol.-Ren. Physiol. 2004, 286, F546-F551. [CrossRef] [PubMed]

20. Eder, P.; Probst, D.; Rosker, C.; Poteser, M.; Wolinski, H.; Kohlwein, S.D.; Romanin, C.; Groschner, K. Phospholipase C-dependent control of cardiac calcium homeostasis involves a TRPC3-NCX1 signaling complex. Cardiovasc. Res. 2007, 73, 111-119. [CrossRef] [PubMed]

21. Rosker, C.; Graziani, A.; Lukas, M.; Eder, P.; Zhu, M.X.; Romanin, C.; Groschner, K. Ca ${ }^{2+}$ signaling by TRPC3 involves $\mathrm{Na}^{+}$entry and local coupling to the $\mathrm{Na}^{+} / \mathrm{Ca}^{2+}$ exchanger. J. Biol. Chem. 2004, 279, 13696-13704. [CrossRef] [PubMed]

22. Doleschal, B.; Primessnig, U.; Wolkart, G.; Wolf, S.; Schernthaner, M.; Lichtenegger, M.; Glasnov, T.N.; Kappe, C.O.; Mayer, B.; Antoons, G.; et al. TRPC3 contributes to regulation of cardiac contractility and arrhythmogenesis by dynamic interaction with NCX. Cardiovasc. Res. 2015, 106, 163-173. [CrossRef] [PubMed]

23. Lichtenegger, M.; Groschner, K. TRPC3: A multifunctional signaling molecule. Handb. Exp. Pharmacol. 2014, 222, 67-84. [PubMed]

24. Riccio, A.; Medhurst, A.D.; Mattei, C.; Kelsell, R.E.; Calver, A.R.; Randall, A.D.; Benham, C.D.; Pangalos, M.N. mRNA distribution analysis of human TRPC family in CNS and peripheral tissues. Brain Res. Mol. Brain Res. 2002, 109, 95-104. [CrossRef]

25. Bush, E.W.; Hood, D.B.; Papst, P.J.; Chapo, J.A.; Minobe, W.; Bristow, M.R.; Olson, E.N.; McKinsey, T.A. Canonical Transient Receptor Potential Channels Promote Cardiomyocyte Hypertrophy through Activation of Calcineurin Signaling. J. Biol. Chem. 2006, 281, 33487-33496. [CrossRef] [PubMed] 
26. Onohara, N.; Nishida, M.; Inoue, R.; Kobayashi, H.; Sumimoto, H.; Sato, Y.; Mori, Y.; Nagao, T.; Kurose, H. TRPC3 and TRPC6 are essential for angiotensin II-induced cardiac hypertrophy. EMBO J. 2006, 25, 5305-5316. [CrossRef] [PubMed]

27. Poteser, M.; Schleifer, H.; Lichtenegger, M.; Schernthaner, M.; Stockner, T.; Kappe, C.O.; Glasnov, T.N.; Romanin, C.; Groschner, K. PKC-dependent coupling of calcium permeation through transient receptor potential canonical 3 (TRPC3) to calcineurin signaling in HL-1 myocytes. Proc. Natl. Acad. Sci. USA 2011, 108, 10556-10561. [CrossRef] [PubMed]

28. Harada, M.; Luo, X.; Qi, X.Y.; Tadevosyan, A.; Maguy, A.; Ordog, B.; Ledoux, J.; Kato, T.; Naud, P.; Voigt, N.; et al. Transient Receptor Potential Canonical-3 Channel-Dependent Fibroblast Regulation in Atrial Fibrillation. Circulation 2012, 126, 2051-2064. [CrossRef] [PubMed]

29. Numaga-Tomita, T.; Kitajima, N.; Kuroda, T.; Nishimura, A.; Miyano, K.; Yasuda, S.; Kuwahara, K.; Sato, Y.; Ide, T.; Birnbaumer, L.; et al. TRPC3-GEF-H1 axis mediates pressure overload-induced cardiac fibrosis. Sci. Rep. 2016, 6, 1-12. [CrossRef] [PubMed]

30. Thodeti, C.K.; Paruchuri, S.; Meszaros, J.G. A TRP to cardiac fibroblast differentiation. Channels 2014, 7, 211-214. [CrossRef] [PubMed]

31. Groschner, K.; Hingel, S.; Lintschinger, B.; Balzer, M.; Romanin, C.; Zhu, X.; Schreibmayer, W. Trp proteins form store-operated cation channels in human vascular endothelial cells. FEBS Lett. 1998, 437, 101-106. [CrossRef]

32. Yip, H.; Chan, W.-Y.; Leung, P.-C.; Kwan, H.-Y.; Liu, C.; Huang, Y.; Michel, V.; Yew, D.T.-W.; Yao, X. Expression of TRPC homologs in endothelial cells and smooth muscle layers of human arteries. Histochem. Cell Biol. 2004, 122, 553-561. [CrossRef] [PubMed]

33. Senadheera, S.; Kim, Y.; Grayson, T.H.; Toemoe, S.; Kochukov, M.Y.; Abramowitz, J.; Housley, G.D.; Bertrand, R.L.; Chadha, P.S.; Bertrand, P.P.; et al. Transient receptor potential canonical type 3 channels facilitate endothelium-derived hyperpolarization-mediated resistance artery vasodilator activity. Cardiovasc. Res. 2012, 95, 439-447. [CrossRef] [PubMed]

34. Huang, J.-H.; He, G.-W.; Xue, H.-M.; Yao, X.-Q.; Liu, X.-C.; Underwood, M.J.; Yang, Q. TRPC3 channel contributes to nitric oxide release: Significance during normoxia and hypoxia-reoxygenation. Cardiovasc. Res. 2011, 91, 472-482. [CrossRef] [PubMed]

35. Dietrich, A.; Mederos y Schnitzler, M.; Gollasch, M.; Gross, V.; Storch, U.; Dubrovska, G.; Obst, M.; Yildirim, E.; Salanova, B.; Kalwa, H.; et al. Increased vascular smooth muscle contractility in TRPC6-/- mice. Mol. Cell. Biol. 2005, 25, 6980-6989. [CrossRef] [PubMed]

36. Koenig, S.; Schernthaner, M.; Maechler, H.; Kappe, C.O.; Glasnov, T.N.; Hoefler, G.; Braune, M.; Wittchow, E.; Groschner, K. A TRPC3 blocker, ethyl-1-(4-(2,3,3-trichloroacrylamide) phenyl)-5-(trifluoromethyl)-1H-pyrazole-4-carboxylate (Pyr3), prevents stent-induced arterial remodeling. J. Pharmacol. Exp. Ther. 2013, 344, 33-40. [CrossRef] [PubMed]

37. Hartmann, J.; Konnerth, A. Mechanisms of metabotropic glutamate receptor-mediated synaptic signalling in cerebellar Purkinje cells. Acta Physiol. 2009, 195, 79-90. [CrossRef]

38. Becker, E.B.E.; Oliver, P.L.; Glitsch, M.D.; Banks, G.T.; Achilli, F.; Hardy, A.; Nolan, P.M.; Fisher, E.M.C.; Davies, K.E. A point mutation in TRPC 3 causes abnormal Purkinje cell development and cerebellar ataxia in moonwalker mice. Proc. Natl. Acad. Sci. USA 2009, 106, 6706-6711. [CrossRef] [PubMed]

39. Fogel, B.L.; Hanson, S.M.; Becker, E.B.E. Do mutations in the murine ataxia gene TRPC3 cause cerebellar ataxia in humans? Mov. Disord. 2015, 30, 284-286. [CrossRef] [PubMed]

40. Neuner, S.M.; Wilmott, L.A.; Hope, K.A.; Hoffmann, B.; Chong, J.A.; Abramowitz, J.; Birnbaumer, L.; O'Connell, K.M.; Tryba, A.K.; Greene, A.S.; et al. TRPC3 channels critically regulate hippocampal excitability and contextual fear memory. Behav. Brain Res. 2015, 281, 69-77. [CrossRef] [PubMed]

41. Cohen, R.; Torres, A.; Ma, H.T.; Holowka, D.; Baird, B. Ca ${ }^{2+}$ Waves Initiate Antigen-Stimulated Ca ${ }^{2+}$ Responses in Mast Cells. J. Immunol. 2009, 183, 6478-6488. [CrossRef] [PubMed]

42. Fanger, C.M.; Hoth, M.; Crabtree, G.R.; Lewis, R.S. Characterization of T cell mutants with defects in capacitative calcium entry: Genetic evidence for the physiological roles of CRAC channels. J. Cell Biol. 1995, 131, 655-667. [CrossRef] [PubMed] 
43. Philipp, S.; Strauss, B.; Hirnet, D.; Wissenbach, U.; Méry, L.; Flockerzi, V.; Hoth, M. TRPC3 Mediates T-cell Receptor-dependent Calcium Entry in Human T-lymphocytes. J. Biol. Chem. 2003, 278, 26629-26638. [CrossRef] [PubMed]

44. Wenning, A.S.; Neblung, K.; Strauss, B.; Wolfs, M.-J.; Sappok, A.; Hoth, M.; Schwarz, E.C. TRP expression pattern and the functional importance of TRPC3 in primary human T-cells. Biochim. Biophys. Acta 2011, 1813, 412-423. [CrossRef] [PubMed]

45. Bernardini, M.; Fiorio Pla, A.; Prevarskaya, N.; Gkika, D. Human transient receptor potential (TRP) channel expression profiling in carcinogenesis. Int. J. Dev. Biol. 2015, 59, 399-406. [CrossRef] [PubMed]

46. Oda, K.; Umemura, M.; Nakakaji, R.; Tanaka, R.; Sato, I.; Nagasako, A.; Oyamada, C.; Baljinnyam, E.; Katsumata, M.; Xie, L.-H.; et al. Transient receptor potential cation 3 channel regulates melanoma proliferation and migration. J. Physiol. Sci. 2017, 67, 497-505. [CrossRef] [PubMed]

47. Jiang, H.-N.; Zeng, B.; Zhang, Y.; Daskoulidou, N.; Fan, H.; Qu, J.-M.; Xu, S.-Z. Involvement of TRPC channels in lung cancer cell differentiation and the correlation analysis in human non-small cell lung cancer. PLoS ONE 2013, 8, e67637. [CrossRef] [PubMed]

48. Kim, J.-M.; Heo, K.; Choi, J.; Kim, K.; An, W. The histone variant MacroH2A regulates $\mathrm{Ca}^{2+}$ influx through TRPC3 and TRPC6 channels. Oncogenesis 2013, 2, e77. [CrossRef] [PubMed]

49. Yang, S.L.; Cao, Q.; Zhou, K.C.; Feng, Y.J.; Wang, Y.Z. Transient receptor potential channel C3 contributes to the progression of human ovarian cancer. Oncogene 2009, 28, 1320-1328. [CrossRef] [PubMed]

50. Aydar, E.; Yeo, S.; Djamgoz, M.; Palmer, C. Abnormal expression, localization and interaction of canonical transient receptor potential ion channels in human breast cancer cell lines and tissues: A potential target for breast cancer diagnosis and therapy. Cancer Cell Int. 2009, 9, 23. [CrossRef] [PubMed]

51. Seo, K.; Rainer, P.P.; Lee, D.I.; Hao, S.; Bedja, D.; Birnbaumer, L.; Cingolani, O.H.; Kass, D.A. Hyperactive Adverse Mechanical Stress Responses in Dystrophic Heart Are Coupled to Transient Receptor Potential Canonical 6 and Blocked by cGMP-Protein Kinase G Modulation. Circ. Res. 2014, 114, 823-832. [CrossRef] [PubMed]

52. Lintschinger, B.; Balzer-Geldsetzer, M.; Baskaran, T.; Graier, W.F.; Romanin, C.; Zhu, M.X.; Groschner, K. Coassembly of Trp1 and Trp3 proteins generates diacylglycerol- and $\mathrm{Ca}^{2+}$-sensitive cation channels. J. Biol. Chem. 2000, 275, 27799-27805. [PubMed]

53. Strübing, C.; Krapivinsky, G.; Krapivinsky, L.; Clapham, D.E. Formation of Novel TRPC Channels by Complex Subunit Interactions in Embryonic Brain. J. Biol. Chem. 2003, 278, 39014-39019. [CrossRef] [PubMed]

54. Poteser, M.; Graziani, A.; Rosker, C.; Eder, P.; Derler, I.; Kahr, H.; Zhu, M.X.; Romanin, C.; Groschner, K. TRPC3 and TRPC4 associate to form a redox-sensitive cation channel. Evidence for expression of native TRPC3-TRPC4 heteromeric channels in endothelial cells. J. Biol. Chem. 2006, 281, 13588-13595. [CrossRef] [PubMed]

55. Zhu, X.; Jiang, M.; Birnbaumer, L. Receptor-activated $\mathrm{Ca}^{2+}$ influx via human Trp3 stably expressed in human embryonic kidney (HEK) 293 cells. Evidence for a non-capacitative Ca ${ }^{2+}$ entry. J. Biol. Chem. 1998, 273, 133-142. [CrossRef] [PubMed]

56. Kamouchi, M.; Philipp, S.; Flockerzi, V.; Wissenbach, U.; Mamin, A.; Raeymaekers, L.; Eggermont, J.; Droogmans, G.; Nilius, B. Properties of heterologously expressed hTRP3 channels in bovine pulmonary artery endothelial cells. J. Physiol. 1999, 2, 345-358. [CrossRef]

57. Ishikawa, J.; Ohga, K.; Yoshino, T.; Takezawa, R.; Ichikawa, A.; Kubota, H.; Yamada, T. A Pyrazole Derivative, YM-58483, Potently Inhibits Store-Operated Sustained Ca ${ }^{2+}$ Influx and IL-2 Production in T Lymphocytes. J. Immunol. 2003, 170, 4441-4449. [CrossRef] [PubMed]

58. Zitt, C.; Strauss, B.; Schwarz, E.C.; Spaeth, N.; Rast, G.; Hatzelmann, A.; Hoth, M. Potent Inhibition of Ca ${ }^{2+}$ Release-activated $\mathrm{Ca}^{2+}$ Channels and T-lymphocyte Activation by the Pyrazole Derivative BTPJ. Biol. Chem. 2004, 279, 12427-12437. [CrossRef] [PubMed]

59. He, L.-P.; Hewavitharana, T.; Soboloff, J.; Spassova, M.A.; Gill, D.L. A functional link between store-operated and TRPC channels revealed by the 3,5-bis(trifluoromethyl)pyrazole derivative, BTP. J. Biol. Chem. 2005, 280, 10997-11006. [CrossRef] [PubMed] 
60. Kiyonaka, S.; Kato, K.; Nishida, M.; Mio, K.; Numaga, T.; Sawaguchi, Y.; Yoshida, T.; Wakamori, M.; Mori, E.; Numata, T.; et al. Selective and direct inhibition of TRPC3 channels underlies biological activities of a pyrazole compound. Proc. Natl. Acad. Sci. USA 2009, 106, 5400-5405. [CrossRef] [PubMed]

61. Schleifer, H.; Doleschal, B.; Lichtenegger, M.; Oppenrieder, R.; Derler, I.; Frischauf, I.; Glasnov, T.N.; Kappe, C.O.; Romanin, C.; Groschner, K. Novel pyrazole compounds for pharmacological discrimination between receptor-operated and store-operated Ca 2+entry pathways. Br. J. Pharmacol. 2012, 167, 1712-1722. [CrossRef] [PubMed]

62. Washburn, D.G.; Holt, D.A.; Dodson, J.; McAtee, J.J.; Terrell, L.R.; Barton, L.; Manns, S.; Waszkiewicz, A.; Pritchard, C.; Gillie, D.J.; et al. The discovery of potent blockers of the canonical transient receptor channels, TRPC3 and TRPC6, based on an anilino-thiazole pharmacophore. Bioorganic Med. Chem. Lett. 2013, 23, 4979-4984. [CrossRef] [PubMed]

63. Seo, K.; Rainer, P.P.; Shalkey Hahn, V.; Lee, D.I.; Jo, S.H.; Andersen, A.; Liu, T.; Xu, X.; Willette, R.N.; Lepore, J.J.; et al. Combined TRPC3 and TRPC6 blockade by selective small-molecule or genetic deletion inhibits pathological cardiac hypertrophy. Proc. Natl. Acad. Sci. USA 2014, 111, 1551-1556. [CrossRef] [PubMed]

64. Miehe, S.; Kleemann, H.-W.; Struebing, C. Use of Norgestimate as a Selective Inhibitor of Trpc3, Trpc6 and Trpc7 Ion Channels-European Patent Office-ep 2205247 B1use of Norgestimate as a Selective Inhibitor of Trpc3, Trpc6 and Trpc7 Ion Channels-European Patent Office-EP 2205247 B1 [Internet]. European Patent Office, 2013. Available online: https:/ / patentimages.storage.googleapis.com/41/64/8c/b98422f55179fa/ EP2205247B1.pdf (accessed on 21 July 2018).

65. Maier, T.; Follmann, M.; Hessler, G.; Kleemann, H.-W.; Hachtel, S.; Fuchs, B.; Weissmann, N.; Linz, W.; Schmidt, T.; Löhn, M.; et al. Discovery and pharmacological characterization of a novel potent inhibitor of diacylglycerol-sensitive TRPC cation channels. Br. J. Pharmacol. 2015, 172, 3650-3660. [CrossRef] [PubMed]

66. Lemonnier, L.; Trebak, M.; Putney, J.W., Jr. Complex regulation of the TRPC3, 6 and 7 channel subfamily by diacylglycerol and phosphatidylinositol-4,5-bisphosphate. Cell Calcium 2008, 43, 506-514. [CrossRef] [PubMed]

67. Graziani, A.; Rosker, C.; Kohlwein, S.D.; Zhu, M.X.; Romanin, C.; Sattler, W.; Groschner, K.; Poteser, M. Cellular cholesterol controls TRPC3 function: Evidence from a novel dominant-negative knockdown strategy. Biochem. J. 2006, 396, 147-155. [CrossRef] [PubMed]

68. Smyth, J.T.; Lemonnier, L.; Vazquez, G.; Bird, G.S.; Putney, J.W. Dissociation of regulated trafficking of TRPC3 channels to the plasma membrane from their activation by phospholipase C. J. Biol. Chem. 2006, 281, 11712-11720. [CrossRef] [PubMed]

69. Dietrich, A.; Mederos y Schnitzler, M.; Emmel, J.; Kalwa, H.; Hofmann, T.; Gudermann, T. N-Linked Protein Glycosylation Is a Major Determinant for Basal TRPC3 and TRPC6 Channel Activity. J. Biol. Chem. 2003, 278, 47842-47852. [CrossRef] [PubMed]

70. Xu, X.; Lozinskaya, I.; Costell, M.; Lin, Z.; Ball, J.A.; Bernard, R.; Behm, D.J.; Marino, J.P.; Schnackenberg, C.G. Characterization of Small Molecule TRPC3 and TRPC6 agonist and Antagonists. Biophys. J. 2013, 104, 454a. [CrossRef]

71. Qu, C.; Ding, M.; Zhu, Y.; Lu, Y.; Du, J.; Miller, M.; Tian, J.; Zhu, J.; Xu, J.; Wen, M.; et al. Pyrazolopyrimidines as Potent Stimulators for Transient Receptor Potential Canonical 3/6/7 Channels. J. Med. Chem. 2017, 60, 4680-4692. [CrossRef] [PubMed]

72. Lutas, A.; Birnbaumer, L.; Yellen, G. Metabolism Regulates the Spontaneous Firing of Substantia Nigra Pars Reticulata Neurons via K ATPand Nonselective Cation Channels. J. Neurosci. 2014, 34, 16336-16347. [CrossRef] [PubMed]

73. Fehrentz, T.; Schönberger, M.; Trauner, D. Optochemical genetics. Angew. Chem. Int. Ed. Engl. 2011, 50, 12156-12182. [CrossRef] [PubMed]

74. Nadler, A.; Reither, G.; Feng, S.; Stein, F.; Reither, S.; Müller, R.; Schultz, C. The fatty acid composition of diacylglycerols determines local signaling patterns. Angew. Chem. Int. Ed. Engl. 2013, 52, 6330-6334. [CrossRef] [PubMed]

75. Tiapko, O.; Bacsa, B.; la Cruz de, G.G.; Glasnov, T.; Groschner, K. Optopharmacological control of TRPC channels by coumarin-caged lipids is associated with a phototoxic membrane effect. Sci. China Life Sci. 2016, 59, 802-810. [CrossRef] [PubMed] 
76. Leinders-Zufall, T.; Storch, U.; Bleymehl, K.; Schnitzler, M.M.Y.; Frank, J.A.; Konrad, D.B.; Trauner, D.; Gudermann, T.; Zufall, F. PhoDAGs Enable Optical Control of Diacylglycerol- Sensitive Transient Receptor Potential Channels. Cell Chem. Biol. 2018, 25, 215-223.e3. [CrossRef] [PubMed]

77. Frank, J.A.; Moroni, M.; Moshourab, R.; Sumser, M.; Lewin, G.R.; Trauner, D. Photoswitchable fatty acids enable optical control of TRPV. Nat. Commun. 2015, 6, 7118. [CrossRef] [PubMed]

78. Frank, J.A.; Yushchenko, D.A.; Hodson, D.J.; Lipstein, N.; Nagpal, J.; Rutter, G.A.; Rhee, J.-S.; Gottschalk, A.; Brose, N.; Schultz, C.; et al. Photoswitchable diacylglycerols enable optical control of protein kinase C. Nat. Chem. Biol. 2016, 12, 755-762. [CrossRef] [PubMed]

(C) 2018 by the authors. Licensee MDPI, Basel, Switzerland. This article is an open access article distributed under the terms and conditions of the Creative Commons Attribution (CC BY) license (http:/ / creativecommons.org/licenses/by/4.0/). 